occur, either the emotional or physical aspects can, of course, be examined further, but over-investigation has its own dangers.

Psychiatric Disease. - There have been claims (Frommer and Cotham, 1970) that recurrent abdominal pain in childhood is commonly a manifestation of depressive illness, and accordingly may be treated with antidepressive drugs. In our experience depression, occurring with the pains or developing later in life, is not common. Among our cases, at the most one in $\mathbf{1 0}$ may be so labelled. A far more usual factor is anxiety.

"Painful Families".- The present series has again confirmed the high incidence of pains in the patient's family (Apley, 1959). The family pains were mainly abdominal: in 11 of 30 cases one (or occasionally both) parents had abdominal symptoms. Pains elsewhere, and migraine, were common too and "nerves" even commoner. We have learned to ask twice as we obtain a more accurate history, and higher figures, when the parents have had time to think the questions over. The child with recurrent pain who comes from a painful family is most unlikely to grow up symptom-free: he has an equal chance of losing the abdominal pains but nearly always develops other symptoms.
Treatment.-The treatment given has been called "informal psychotherapy." It is reassurance based on explanations and discussions. It cannot be claimed to have "cured" the pains, but it was helpful in speeding the recovery from attacks of pain and lessening the occurrence of other symptoms, both physical and nervous. It seemed also to increase the patient's adaptability and make it more likely that he could live a normal life. In our follow-up of treated cases, half the patients were interviewed with their parents. Years after treatment was finished these parents emphasized, time and again, the good effects of reassurance with explanations and discussions both on themselves and on their children. After all, the family is a unit of disease.

\section{References}

Apley, J. (1959). The Child with Abdominal Pains. Oxford, Blackwell Scientific.

Apley, J., and Naish, N. (1958). Archives of Disease in Childhood, 33, 165 Apley, J., and Naish, N. (1958). Archives of Disease in Childhood, 33, 165. Oxford Blackwell Scientific.

Frommer, E., and Cotham, D. (1970). British Medical fournal, 4, 113.

\title{
Evaluation of Chlorpropamide in Chemical Diabetes Diagnosed during Pregnancy
}

\author{
H. W. SUTHERLAND, J. M. STOWERS, J. D. CORMACK, P. D. BEWSHER
}

British Medical fournal, 1973, 3, 9-13

\section{Summary}

The intravenous glucose tolerance test (I.V.G.T.T.) was used to diagnose chemical diabetes during pregnancy in 180 women, 50 of whom subsequently received chlorpropamide therapy in a daily dosage of $100 \mathrm{mg}$; the remainder had no drug therapy.

Preliminary work shored the I.V.G.T.T. to be reproducible in the second and third trimesters but not in the puerperium in normal pregnancy. Though intravenous glucose tolerance deteriorates between the second and third trimesters in women with no features of diabetes, a significant improvement occurs after a course of chlorpropamide in a daily dosage of $100 \mathrm{mg}$ during pregnancy in chemical diabetes, but this treatment did not enhance the rate of return to normal glucose tolerance post partum.

Plasma glucose and insulin studies showed no evidence of hypoglycaemia or hyperinsulinism in the mother at

University Department of Obstetrics and Gynaecology, Maternity Hospital, Foresterhill, Aberdeen AB9 2ZA

H. W. SUTHERLAND, M.B., M.R.C.o.G., Senior Lecturer and Honorary Consultant

Diabetic Clinic, Aberdeen Royal Infirmary, Woolmanhill AB9 1GS

J. M. STOWERS, M.D., F.R.C.P., Consultant Physician in charge of Diabetic Service

Royal Aberdeen Children's Hospital, Foresterhill, Aberdeen AB9 2ZA

J. D. CORMACK, M.B., D.oBsT., R.C.o.G., Registrar in Paediatric Medicine (Present address: 468 Anthony Drive, Oakville, Ontario, Canada)

University Department of Therapeutics and Clinical Pharmacology, University Medical Buildings, Foresterhill, Aberdeen AB9 2ZD

P. D. BEWSHER, M.D., M.R.C.P., Senior Lecturer in Therapeutics and Honorary Consultant Physician delivery or in the newborn when chlorpropamide had been used compared with a group receiving no such treatment. In the infants of the chlorpropamide-treated mothers there was a suggestion of an increased rate of glucose disposal in response to a glucose challenge, but no increase in birth weight.

There were two fetal deaths in the 50 pregnancies of mothers treated with chlorpropamide, one being due to a mistaken premature delivery and the other to a diaphragmatic hernia. Thus chlorpropamide in a dose of $100 \mathrm{mg}$ a day has been shown to reverse chemical diabetes diagnosed and treated in pregnancy without apparent risk to the fetus.

\section{Introduction}

This paper is concerned with chemical diabetes diagnosed for the first time during pregnancy. Chemical diabetes has been defined as an abnormal response to a glucose load but with a fasting capillary blood glucose value not exceeding $130 \mathrm{mg} /$ $100 \mathrm{ml}$ (FitzGerald and Keen, 1964). This form of diabetes has been described otherwise as "asymptomatic" or "subclinical" (subgroup "a," FitzGerald and Keen, 1964).

In our experience chemical diabetes occurs about six times more frequently in pregnancy than the overt variety, so it is important to know if there is an increased risk to the fetus in this mild degree of diabetes, though it is well known there is an increased risk in the prediabetic period in general (Miller, 1945; Malins and FitzGerald, 1965).

There is a consensus that prolonged pregnancy should be avoided and delivery at or before the expected date should be effected when even mild glucose intolerance has been found. In overweight chemical diabetic pregnant subjects dietary treatment during pregnancy is appropriate and may be all that is necessary. In pregnant women of near normal body weight the therapeutic alternatives available to reduce the effects of maternal chemical diabetes are insulin or an oral hypoglycaemic agent such as a sulphonylurea. 
This report concerns the use of the sulphonylurea, chlorpropamide, in a daily dosage of $100 \mathrm{mg}$ in maternal chemical diabetes diagnosed for the first time during pregnancy. Before using this test it was thought important to establish whether the intravenous glucose tolerance test (I.V.G.T.T.) is a reproducible measure of glucose tolerance during pregnancy and to see whether glucose tolerance changes in normal women during the course of pregnancy. We describe the changes induced by chlorpropamide in the glucose and insulin values of the newborn infants of chemical gestational diabetic mothers and compare them with the values obtained from infants of mothers not given chlorpropamide. The obstetric outcome of a larger series of pregnancies in which chlorpropamide was used is evaluated, and a comparison is made with a group not similarly treated.

\section{Patients and Methods}

The indications for the selection of pregnant women suspected of chemical diabetes for I.V.G.T.T.s were a family history of diabetes, or obesity ( $<85$ th percentile) (Kemsley, 1951-2), or past or present obstetric features-namely, previous delivery of a heavy-for-dates baby ( $<$ 95th percentile) (Thomson et al., 1968), neonatal deaths, stillbirths, two or more abortions, polyhydramnios, or a major congenital abnormality in the fetus. The use of glycosuria as an indication was restricted to true fasting glycosuria (Sutherland et al., 1970). The results of the I.V.G.T.T.s were expressed as increment indices (Duncan, 1956) and levels of 2.97 and below were regarded as abnormal. When a patient was found to have an abnormal increment index further antenatal and medical care was undertaken at a weekly combined antenatal diabetic clinic.

Women with a calculated prepregnancy body weight below the 85th percentile on the Kemsley scale and diagnosed at least two weeks before the expected date of delivery were treated with chlorpropamide $100 \mathrm{mg}$ daily for the remainder of the pregnancy. Our experience with larger doses of chlorpropamide is described elsewhere (Cormack et al., 1971; Sutherland et al., 1973).

When an abnormal test result was found in the last two weeks of pregnancy, admission for surgical induction of labour before term was arranged and no chlorpropamide therapy was given ("untreated group"). This group like the "chlorpropamide group" did have special obstetric care in that most of them had a surgical induction of labour more than five days before the expected date of delivery.

The procedures used to study the effect of maternal chlorpropamide therapy on the newborn were as follows: maternal vein, cord artery, and vein blood samples were withdrawn at delivery for estimation of glucose and insulin concentration. Heel-stab capillary samples were withdrawn at birth, and at 30,60 , and 90 minutes of age for glucose estimation. I.V.G.T.T.s were performed then, in the first four hours after birth, using $0.5 \mathrm{~g}$ of glucose per kilogram body weight in a $20 \%$ solution injected through a heparinized Tizzard catheter in the umbilical vein. Before the injection an umbilical venous sample was taken for initial blood glucose and plasma insulin values. After the injection the original catheter was discarded and replaced with a fresh catheter from which blood specimens were taken at 5, 15,30 , and 60 minutes after the glucose. After withdrawing the umbilical catheter a nasogastric tube was inserted through which feeding with $10 \%$ glucose was started, gradually progressing to three-hourly full-strength half cream milk by the third day of life.

Samples for blood glucose estimations were pipetted into distilled water and the proteins precipitated immediately with $0.4 \mathrm{ml}$ of $5 \%$ zinc sulphate and $0.4 \mathrm{ml}$ of $0.3 \mathrm{~N}$ sodium hydroxide solution. Whole blood glucose was estimated by a standard manual glucose oxidase method (Hugget and Nixon, 1959). Plasma immunoreactive insulin was estimated by the method of Hales and Randle (1963).

\section{Results}

\section{MATERNAL}

Fifty women had chlorpropamide therapy in a daily dosage of $100 \mathrm{mg}$ for not less than six weeks in late pregnancy (mean $7.5 \pm 1$ weeks) and 130 women were not given chlorpropamide as the diagnosis was made within two weeks of delivery. None in either group developed symptomatic diabetes during the observed pregnancies.

In this study the assessment of the effect of chlorpropamide on glucose tolerance in pregnancy depends on the reproducibility of the I.V.G.T.T. in the second and third trimesters of pregnancy. An assessment of this was made before the trial of chlorpropamide was started and the results are summarized in table I. The subjects studied were selected on the basis of no stigmata suggestive of diabetes based on obstetric and family history of diabetes, the absence of pregnancy glycosuria, and they were all below the 85th percentile of body weight. Four such women had paired intravenous glucose tolerance tests one week apart in the second and third trimesters and postpartum. Two further women had paired tests in the second and third trimesters only and a further two in the third trimester and postpartum only. The degree of association of the results of the paired tests expressed as correlation coefficients was found to be significant in the second and third trimesters but not postpartum.

The results of seven consecutive chemical diabetic pregmant women treated with chlorpropamide for a mean duration of 11 weeks and retested in late pregnancy three weeks after stopping the chlorpropamide therapy are given in table II. Such is the uniform improvement in the rate of glucose disposal that the later test result in each case falls within the normal rangethat is, greater than 2.97. The improvement in these chlorpropamide-treated cases is statistically highly significant if one assumes that there would have been no change in the increment

TABLE I-Degree of Association of Successive Increment Indices (I.I.) in Normal Pregnancies

\begin{tabular}{|c|c|c|c|c|c|c|c|c|c|c|c|c|}
\hline \multirow{3}{*}{ Case No. } & \multicolumn{12}{|c|}{ Time of Test } \\
\hline & \multicolumn{4}{|c|}{ 2nd Trimester } & \multicolumn{4}{|c|}{ 3rd Trimester } & \multicolumn{4}{|c|}{ Postpartum } \\
\hline & I.I. & week & I.I. & week & I.I. & week & I.I. & week & I.I. & week & I.I. & week \\
\hline $\begin{array}{l}1 \\
2 \\
3 \\
4 \\
5 \\
6 \\
7 \\
8\end{array}$ & $\begin{array}{l}4.08 \\
6.93 \\
5.37 \\
5.55 \\
4.95 \\
4.08\end{array}$ & $\begin{array}{l}22 \\
18 \\
24 \\
25 \\
\frac{23}{24}\end{array}$ & $\begin{array}{l}3.75 \\
6.30 \\
6.03 \\
5.55 \\
4.77 \\
4.62\end{array}$ & $\begin{array}{l}23 \\
19 \\
25 \\
26 \\
\frac{24}{25}\end{array}$ & $\begin{array}{l}4.68 \\
6.93 \\
5.12 \\
5.55 \\
5.37 \\
4.08 \\
4.08 \\
3.76\end{array}$ & $\begin{array}{l}31 \\
34 \\
37 \\
34 \\
37 \\
34 \\
39 \\
34\end{array}$ & $\begin{array}{l}4.62 \\
6.03 \\
5.12 \\
5.78 \\
6.30 \\
4.95 \\
4.95 \\
3.65\end{array}$ & $\begin{array}{l}32 \\
35 \\
38 \\
35 \\
38 \\
35 \\
40 \\
35\end{array}$ & $\begin{array}{l}\overline{7.70} \\
4.95 \\
7.70 \\
5.37 \\
\overline{4.95} \\
8.15\end{array}$ & $\begin{array}{l}79 \\
5 \\
7 \\
8 \\
4 \\
4\end{array}$ & $\begin{array}{l}\overline{6.30} \\
4.33 \\
6.93 \\
7.70 \\
7.77 \\
7.70\end{array}$ & $\begin{array}{r}\overline{10} \\
6 \\
8 \\
9 \\
5 \\
5\end{array}$ \\
\hline Mean \pm S.D. & \multicolumn{2}{|c|}{$5 \cdot 16 \pm 1 \cdot 07$} & \multicolumn{2}{|c|}{$5.17 \pm 0.96$} & \multicolumn{2}{|c|}{$4.95 \pm 1.03$} & \multicolumn{2}{|c|}{$5 \cdot 18 \pm 0 \cdot 85$} & \multicolumn{2}{|c|}{$6.47 \pm 1.53$} & \multicolumn{2}{|c|}{$6.79 \pm 1.34$} \\
\hline $\begin{array}{l}\text { No. of paired tests } \\
\text { Correlation coefficient } \\
\text { Significance }\end{array}$ & \multicolumn{4}{|c|}{$\begin{array}{l}6 \\
0.94 \\
P>0.01\end{array}$} & \multicolumn{4}{|c|}{$\begin{array}{c}8 \\
0.68 \\
P>0.05\end{array}$} & \multicolumn{4}{|c|}{$\begin{array}{l}6 \\
0.43 \\
\text { Not gignificant }\end{array}$} \\
\hline
\end{tabular}


TABLE II-Increment Indices before and after Chlorpropamide Therapy for Chemical Diabetes Diagnosed in Pregnancy

\begin{tabular}{c|c|c|c}
\hline Case No. & $\begin{array}{c}\text { Weeks of Treatment } \\
(100 \text { mg/day })\end{array}$ & $\begin{array}{c}\text { Increment Index } \\
\text { before Treatment }\end{array}$ & $\begin{array}{c}\text { Increment Index } \\
\text { Three Weeks After } \\
\text { Stopping Treatment }\end{array}$ \\
\hline 1 & 10 & 2.67 & 3.22 \\
2 & 10 & $2 \cdot 71$ & 4.33 \\
3 & 14 & $2 \cdot 27$ & 3.22 \\
4 & 10 & $2 \cdot 83$ & 3.65 \\
5 & 11 & 2.52 & 3.85 \\
6 & 10 & $2 \cdot 48$ & 4.95 \\
7 & 11 & 2.52 & $* 3.81$ \\
\hline Mean & 10 & \\
\hline
\end{tabular}

$* P<0.005$ assuming no change in increment index without the use of chlorpropamide.

index without this treatment. In fact there is likely to be a slight lowering of increment index with time at this stage of pregnancy (Solomons et al., 1963) so that it may be fairer to compare the increment index noted at this stage in 20 (which includes the six in table I) normal patients selected for study because of the absence of diabetic stigmata (see table III). Indeed our own figures tend to confirm this in the six women who had paired

TABLE III-Changes in I.V.G.T.T. between 2nd and 3rd Trimesters in Normal Non-diabetic Women and in Chemical Diabetic Women Treated with Chlorpropamide until Three Weeks before Repeat Test in 3rd Trimester. (Mean \pm S.E. of Mean)

\begin{tabular}{|c|c|c|c|c|}
\hline Subjects & $\begin{array}{c}\text { Mean } \\
\text { Increment } \\
\text { Index } \\
\text { 2nd Trimester }\end{array}$ & $\begin{array}{c}\text { Mean } \\
\text { Increment } \\
\text { Index } \\
\text { 3rd Trimester }\end{array}$ & Difference & Significance \\
\hline $\begin{array}{l}\text { Non-diabetic }(n=20) \\
\text { Chemical diabetes } \\
\text { treated with } \\
\text { chlorpropamide } \\
(n=7) \quad \ldots\end{array}$ & $\begin{array}{l}5 \cdot 11 \pm 0.29 \\
2.52 \pm 0.90\end{array}$ & $4 \cdot 92 \pm 0 \cdot 23$ & $\begin{array}{l}-0.19 \\
+1.29\end{array}$ & \}$P=<0.01$ \\
\hline
\end{tabular}

tests during the second and third trimesters. The mean increment indices were 5.17 and 5.02 respectively though this difference is not statistically significant.

Information regarding the effect of chlorpropamide on the change in increment index between the time of diagnosis in pregnancy and at about six weeks postpartum is given in table IV. There was an improvement in the increment index in 35

TABLE IV-Comparisons of Antenatal and Postnatal I.V.G.T.T.s in Chemical Diabetes treated with Chlorpropamide and Untreated. (Mean \pm S.E. of Mean

\begin{tabular}{|c|c|c|c|c|}
\hline & $\begin{array}{c}\text { Mean } \\
\text { Antenatal } \\
\text { Increment } \\
\text { Index }\end{array}$ & $\begin{array}{c}\text { Mean } \\
\text { Postnatal } \\
\text { Increment } \\
\text { Index }\end{array}$ & $\begin{array}{c}\text { Mean of } \\
\text { Differences }\end{array}$ & $\begin{array}{l}\text { Percentage of } \\
\text { Subjects with } \\
\text { Improved } \\
\text { Glucose } \\
\text { Tolerance }\end{array}$ \\
\hline $\begin{array}{l}\text { Chlorpropamide }(n=39) \\
\text { Untreated }(n=93) \quad \ldots \\
\text { P value .. } \quad . .\end{array}$ & $\begin{array}{l}2.39 \pm 0.07 \\
2.61 \pm 0.05 \\
<0.05\end{array}$ & $\begin{array}{l}4.0 \pm 0.26 \\
4.07 \pm 0.19 \\
<0 \cdot 10\end{array}$ & $\begin{array}{c}1.61 \pm 0.27 \\
1.46 \pm 0.18 \\
<0.10\end{array}$ & $\begin{array}{l}89 \cdot 8 \\
81.5 \\
<0.95\end{array}$ \\
\hline
\end{tabular}

* Significant.

of 39 of those treated with chlorpropamide, and 76 of 93 of the untreated chemical diabetics postpartum. There is no significant difference between the improvements in increment indices post- partum in these two groups. However, the chlorpropamidetreated group had significantly more severe diabetes than the untreated group when tested in pregnancy, whereas the postpartum increment indices in the two groups were almost identical, clearly in the normal range.

\section{FETAL METABOLISM}

The most significant action of the sulphonylureas is to stimulate insulin secretion and it is theoretically a valid fear that because chlorpropamide is transferred by the placenta to the fetal compartment (Stowers et al., 1973) fetal hyperinsulinism (Stimmler et al., 1964; Jgrgensen et al., 1966) may be accentuated by maternal chlorpropamide therapy (Kemball et al., 1970). This might add to the already existing risk of fetal islet hyperplasia resulting from stimulation from inappropriately high levels of blood glucose of maternal origin in utero producing neonatal hypoglycaemia in the infant of the diabetic mother. One parameter of fetal hyperinsulinism is percentile birth weight which could reasonably be expected to be high from the resulting excessive lipogenesis in the fetus.

The birth weights of the infants of the chlorpropamidetreated and untreated mothers allocated to the percentiles of birth weight derived from a study of 52,004 Aberdeen birth weights (Thomson et al., 1968) are shown in fig. 1. Allowance

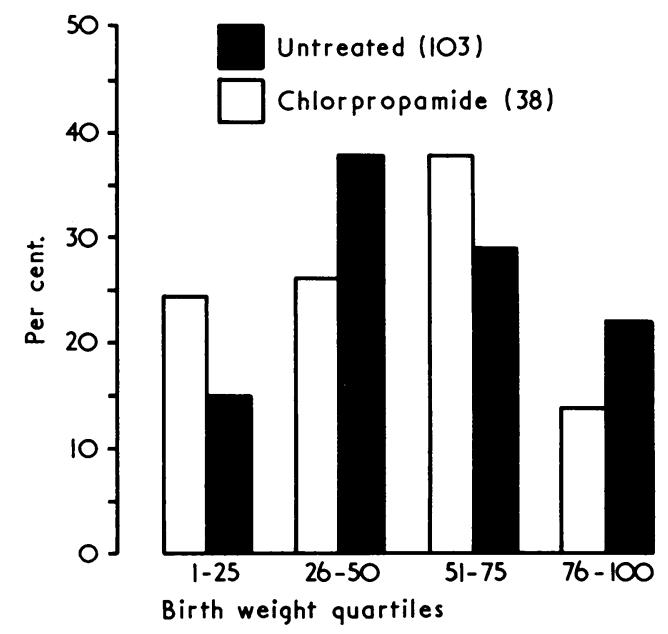

FIG. 1-Effect on infant birth weight of treatment of maternal chemical diabetes with chlorpropamide.

is made for gestational age, sex of baby, maternal height, weight for height, parity, and social class in the two groups. It can be concluded that maternal chlorpropamide therapy did not produce excessive weight of the fetus in utero.

Further evidence of the effect of possible chlorpropamideinduced fetal hyperinsulinism was sought. Data in a series of consecutive diabetic pregnant women treated with chlorpropamide and another consecutive series not given chlorpropamide are given in table $\mathrm{V}$. The figures represent glucose and insulin levels in maternal venous, cord venous, and arterial blood taken at delivery. There is no evidence of maternal

TABLB V-Comparison of Blood Glucose and Plasma Insulin Levels at Delivery in Untreated and Chlorpropamide-treated Chemical Diabetes. (Mean \pm S.E. of Mean)

\begin{tabular}{|c|c|c|c|c|c|c|c|}
\hline \multirow{2}{*}{\multicolumn{2}{|c|}{ Antenatal Treatment }} & \multicolumn{2}{|c|}{ Maternal Vein } & \multicolumn{2}{|c|}{ Cord Vein } & \multicolumn{2}{|c|}{ Cord Artery } \\
\hline & & $\begin{array}{l}\text { Glucose } \\
(\mathrm{mg} / 100 \mathrm{ml})\end{array}$ & $\begin{array}{l}\text { Insulin } \\
(\mu \mathrm{U} / \mathrm{ml})\end{array}$ & $\begin{array}{c}\text { Glucose } \\
(\mathrm{mg} / 100 \mathrm{ml})\end{array}$ & $\begin{array}{l}\text { Insulin } \\
(\mu \mathrm{U} / \mathrm{ml})\end{array}$ & $\begin{array}{c}\text { Glucose } \\
\text { (mg/100 ml) }\end{array}$ & $\underset{(\mu \mathrm{U} / \mathrm{ml})}{\text { Insulin }}$ \\
\hline $\begin{array}{l}\text { None }(n=8) \\
\text { Chlorpropamide }(n=12)(100 \mathrm{mg} / \ddot{\text { day }})\end{array}$ & $\because$ & $\begin{array}{l}134 \pm 19 \\
123 \pm 8\end{array}$ & $\begin{array}{l}33 \pm 8 \\
29 \pm 5\end{array}$ & $\begin{array}{c}114 \pm 14 \\
95 \pm 6\end{array}$ & $\begin{array}{l}22 \pm 4 \\
18 \pm 2\end{array}$ & $\begin{array}{l}96 \pm 15 \\
77 \pm 7\end{array}$ & $\begin{array}{l}17 \pm 2 \\
21 \pm 3\end{array}$ \\
\hline
\end{tabular}


hypoglycaemia or hyperinsulinism in the chlorpropamidetreated mothers; nor is there any evidence of fetal hypoglycaemia or hyperinsulinism at the time of delivery. The slightly greater value of plasma insulin in the cord vein compared to the cord artery in the untreated group is not statistically significant. In none of the levels compared is there any significant difference between the two groups.

The capillary blood glucose levels in the first 90 minutes of life in relation to the cord artery levels at birth in infants of chlorpropamide-treated and untreated mothers is shown in fig. 2. The fall in blood glucose is similar in the two groups.

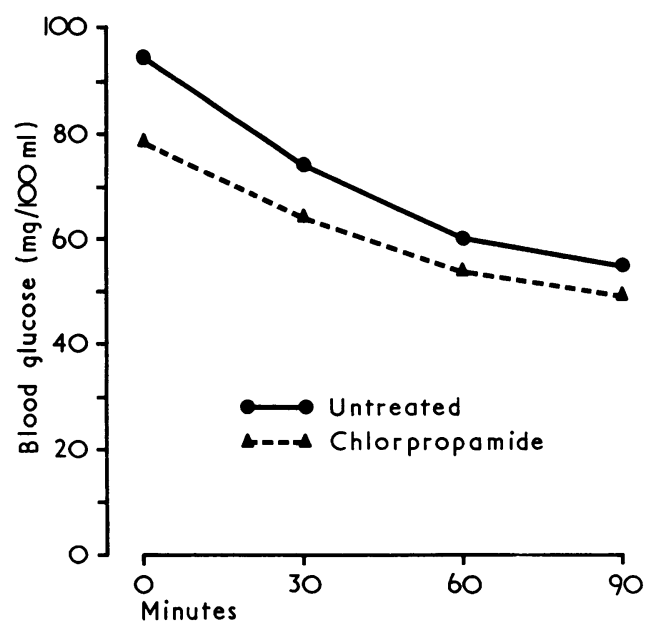

FIG. 2-Blood glucose levels: first 90 minutes after FIG. $2-$ Blood glucose levels: first 90 minutes
birth in infants of chemical diabetic mothers.

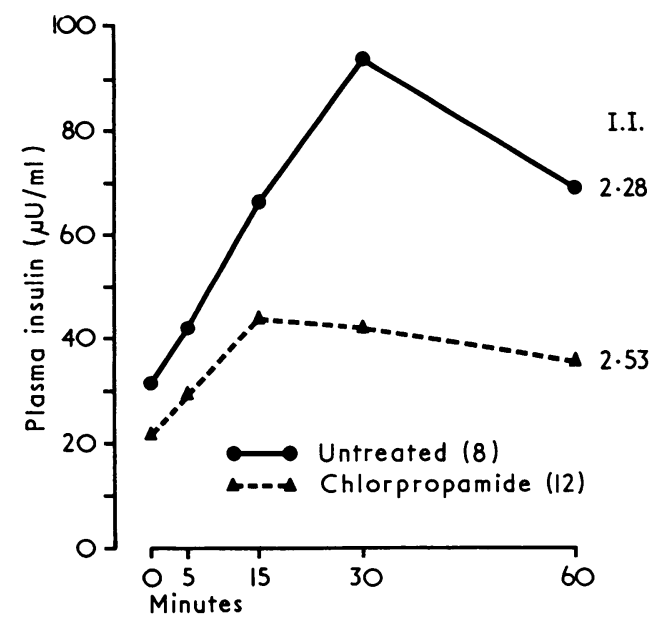

FIG. 3-Plasma insulin and increment indices (I.I.) of I.V.G.T.T.s in infants of untreated and chlorpropamide-treated chemical diabetic mothers.

In fig. 3 the insulin responses to the intravenous glucose challenge in the neonate, with the rates of glucose disposal expressed alongside as the increment indices, are shown in the infants of the two groups of mothers. Though the rate of glucose disposal is greater in the infants of the chlorpropamidetreated mothers, the insulin peak is lower and occurs earlier.

\section{OBSTETRIC FACTORS AND PERINATAL MORTALITY}

A comparison was made between a group of 50 mothers with gestational chemical diabetes who received chlorpropamide and a group of 130 who had no chlorpropamide.
Maternal Age.-The mean age of the chlorpropamide-treated group was $29 \cdot 1 \pm 6.9$ and this was not significantly higher than the untreated group at $27 \cdot 7 \pm 6 \cdot 5$.

Parity.-The mean parity including the index pregnancy of the chlorpropamide-treated group was $3 \cdot 1 \pm 2 \cdot 1$ and this was not significantly higher than the untreated group at $2 \cdot 6 \pm 1.9$.

Social Class.-The social class distribution in the two groups was not significantly different.

Fetal Distress.-The incidence of clinical fetal distress defined as the appearance of fresh meconium staining in the liquor amnii and/or a fetal bradycardia of fewer than 120 beats/ min in labour, was not significantly different, being $2 \%$ in the chlorpropamide-treated group and $8 \%$ in the untreated group.

Induction of Labour. - Surgical induction of labour more than five days before the expected date of delivery was done in $87 \%$ of the untreated group compared with $66 \%$ in the chlorpropamide-treated group.

Mode of Delivery.-The mode of delivery in the chlorpropamide-treated group and the untreated group respectively was as follows: spontaneous vertex delivery, $78 \%$ and $71 \%$; forceps delivery, $6 \%$ and $17 \%$; caesarean section, $14 \%$ and $12 \%$; assisted breech delivery, $2 \%$ and less than $1 \%$.

Perinatal Mortality.-The perinatal mortality in the chlorpropamide-treated group was 40 per 1,000 and in the untreated mothers 8 per 1,000 , which is surprisingly lower than the Aberdeen city rate. The rate for the chlorpropamide-treated group, however, represents two deaths in 50 pregnancies, and for the untreated group only one death in 130 pregnancies. Perhaps a better evaluation of the effect of treatment is a comparison of perinatal mortality in the same subjects in treated and untreated pregnancies. Such a comparison is made in table VI. The perinatal mortality in these subjects fell in the

TABLE VI-Perinatal Mortality in Relation to Treatment of Chemical Diabetes during Pregnancy

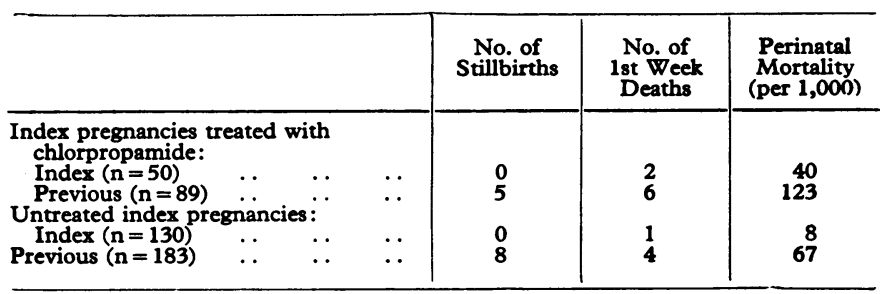

chlorpropamide-treated pregnancy from 123 per 1,000 to 40 per 1,000 . In the untreated group the perinatal mortality fell from 67 to 8 per 1,000 . These differences are not accounted for by the change in mortality between first and subsequent pregnancies in the city of Aberdeen where the rates were 17.3 and 18.3 respectively per 1,000 in 1970 .

\section{Discussion}

This study was initiated only after noting no increase in fetal malformations in women already on oral sulphonylurea therapy at conception and who continued on it through the early months of pregnancy before they reported for antenatal care. Our conclusions that the sulphonylureas had no teratogenic effects in man were supported by the report from the rare diseases subcommittee of the medical and scientific section of the British Diabetic Association (Malins et al., 1964), and by an earlier report from France (Sterne and Lavieuville, 1963).

Interest in the early stages of diabetes has been a recent phenomenon, and the definition given by FitzGerald and Keen for asymptomatic or chemical diabetes (subgroup "a", FitzGerald and Keen, 1964) needs some modification when applied to pregnancy, for in normal pregnancy there is a tendency for 
the fasting blood sugar level to be lower and for the two-hour level after oral glucose to be higher than in the non-pregnant.

The rapid I.V.G.T.T. was chosen for this study because it is well tolerated by women in early pregnancy, even those affected by nausea or vomiting at this time, and it avoids the variability of alimentary absorption associated with pregnancy. In view of this and the results of the reproducibility study done, admittedly in normal pregnancies, we prefer the I.V.G.T.T. in pregnancy to all types of oral glucose tolerance test.

It is noteworthy that the I.V.G.T.T. was not found to be reproducible in the puerperium, and this fact must cast doubt on comparative studies of the validity and sensitivity of different forms of glucose tolerance tests during pregnancy in which the postpartum result is used as the standard of reference. This also must raise doubts on the validity of the term gestational diabetes when a normal postpartum test is used as the standard for comparison. We suggest that gestational diabetes should refer to abnormal glucose tolerance during pregnancy when there is no reason to believe that glucose tolerance was other than normal before pregnancy.

Birth weight was used as a possible assessment of the effect of chlorpropamide given to the mother and passing through the placenta to stimulate insulin secretion in the fetus, but a number of other factors can affect birth weight. Allowance has been made for many of these factors in each patient so that the expected quartile range of birth weight can be compared with that actually found. This assessment provided no evidence that chlorpropamide did increase the birth weight, and indeed, we found that the insulin levels were not increased.

The results of this study not only defend the use of chlorpropamide in a dose of $100 \mathrm{mg} /$ day in chemical diabetes in pregnancy, but also point out an apparent advantage in that it appears to improve glucose tolerance in the mother without producing hyperinsulinism in the fetus. There is a suggestion that chlorpropamide may increase the glucose tolerance of the infant by extrapancreatic effects rather than by stimulating the insulin response.

It is very likely that neither of the two neonatal deaths in the chlorpropamide-treated group were attributable to sulphonylurea therapy. The first death occurred in 1963 and was due to the complications of extreme prematurity after failed induction of labour and caesarean section at 32 weeks' gestation, because the diagnosis of intrauterine growth retardation was mistakenly made. In the second case an infant of average weight at term did not survive the surgical correction of a large diaphragmatic hernia at 72 hours of age. The mothers had received chlorpropamide for 11 and six weeks respectively immediately before delivery.

The low perinatal mortality in the chemical diabetic pregnancies studied is probably due to the policy of intensive antenatal care and delivery before term. The figures indicate a greater fetal risk in the years before the chemical diabetes is diagnosed in the mother than in the pregnancy when the glucose intolerance was found. Though it can be argued that the previous pregnancies contained a large proportion of primigravidae with an associated higher incidence of pre-eclampsia and dysfunctional labours, the perinatal mortality in Aberdeen is not higher in first than in subsequent pregnancies. The increased perinatal mortality found in the earlier pregnancies of mothers subsequently shown to have chemical diabetes may be attributable to their relative disadvantage to withstand the stress of labour and an independent neonatal existence, whether or not there coexists the additional insults of pre-eclampsia or dysfunctional labour so characteristic of first pregnancies.

The lower perinatal mortality in the previous pregnancies of the untreated mothers compared with the chlorpropamidetreated mothers is most likely due to a selective factor arising from the fact that previous stillbirth or neonatal death were used as indicators for glucose tolerance testing in pregnancy. This information was available when the patient originally booked in to the antenatal clinic and this would produce a bias in this group to earlier I.V.G.T.T.s in the index pregnancy and a relative diminution of such cases in the untreated group. This bias in selection would also tend to produce a greater number of poor reproducers in the chlorpropamide-treated group.

Because of this and the apparent increase in the signs of fetal distress in labour in the untreated group it has been decided to undertake a double-blind trial of chlorpropamide therapy (100 mg daily) to study its possible clinical role.

Grateful acknowledgement is made to the British Diabetic Association for the part-time support of H.W.S. and the clerical help provided by Mrs. Kathleen Anderson, and to the Scottish Hospitals Endowment Research Trust for the support given to Mr. Raymond Christie who provided technical help.

It is with pleasure that we express our thanks to Mr. W. R. Bytheway for his statistical advice and to Professor Ian MacGillivray aidd Professor Ross G. Mitchell for their kind co-operation and encouragement.

Requests for reprints should be addressed to: Dr. H. W. Sutherland, Department of Obstetrics and Gynaecology, Aberdeen Maternity Hospital, Foresterhill, Aberdeen AB9 2ZA.

\section{References}

Cormack, J. D., Sutherland, H. W., Stowers, J. M., and Bewsher, P. D. (1971). Proceedings of the 2nd European Congress of Perinatal Medicine, 1970 , p. 257. Basle, Karger.

Duncan, L. J. P. (1956). Fournal of Experimental Physiology, 41, 85.

FitzGerald, M. G., and Keen, H. (1964). Lancet, 1, 1325.

Hales, C. N., and Randle, P. J. (1963). Biochemical fournal, 88, 137.

Jørgensen, K., Deckert, T., Pedersen, L. M., and Pedersen, J. (1966). Acta Endocrinologica (Copenhagen), 52, 154.

Kemball, M. L., et al. (1970). Archives of Disease in Childhood, 45, 696.

Kemball, M. L., et al. (1970). Archives of Disease in Child

Memsley, W. F. F. (1951-2). Annals of Eugenics, 16, 316. British Medical fournal, 2, 187.

Malins, J. M., and FitzGerald, M. G. (1965). Diabetes, 14, 175.

Miller, H. C. (1945). New England fournal of Medicine, 233, 276.

Solomons, E., Silverstone, F. A., and Posner, N. A. (1963). Obstetrics and Gynecology, 22, 50.

Sterne, J., and Lavieuville, M. (1963). Presse Médicale, 71, 1547.

Stimmler, L., Brazie, J. V., and O'Brien, D. (1964). Lancet, 1, 137.

Stowers, J. M., Prescott, L., and Sutherland, H. W. (1973). In preparation.

Sutherland, H. W., et al. (1973). In preparation.

Sutherland, H. W., Stowers, J. M., and McKenzie, C. (1970). Lancet, 1, 1069.

Thomson, A. M., Billewicz, W. Z., and Hytten, F. E. (1968). Fournal of Obstetrics and Gynaecology of the British Commonwealth, 75, 9. 